\title{
False Negative Result
}

National Cancer Institute

\section{Source}

National Cancer Institute. False Negative Result. NCI Thesaurus. Code C63149.

Problem associated with the device incorrectly reporting that something has not been detected and may mislead the operator into not taking certain actions when action should be taken. 